\title{
METHOD OF WRITING DISCURSIVE ESSAYS ON SOCIAL AND PEDAGOGICAL TOPICS
}

\author{
Opaliuk T. L. \\ Doctor of Pedagogical Sciences, Associate Professor of the Department of Social Pedagogy and \\ Social Work of Kamianets-Podilskyi National University named after Ivan Ogienko, \\ Kamianets-Podilskyi, Ukraine.
}

DOI: https://doi.org/10.31435/rsglobal_ws/31032020/6987

\section{ARTICLE INFO \\ Received: 17 January 2020 \\ Accepted: 09 March 2020 \\ Published: 31 March 2020 \\ KEYWORDS \\ discourse, discursive analysis, discursive essay, competence-based education, analytical and reflective activity, social and pedagogical competence.}

\begin{abstract}
The article discusses essential problems of discursive essay writing method during professional formation of a future teacher, conceptual approaches and technique of step-by-step preparation for its writing, as well as approaches to assessing and analyzing the level of performance using defined set of criteria given specifics of social and pedagogical problems. General theoretical bases of interpretation of discourse features and logic and technological support of its implementation are described, given the specifics of essay writing method, which was not relevant in the system of information and reproductive professional education.
\end{abstract}

Citation: Opaliuk T. L. (2020) Method of Writing Discursive Essays on Social and Pedagogical Topics. World Science. 3(55), Vol.3. doi: 10.31435/rsglobal_ws/31032020/6987

Copyright: (C) 2020 Opaliuk T. L. This is an open-access article distributed under the terms of the Creative Commons Attribution License (CC BY). The use, distribution or reproduction in other forums is permitted, provided the original author(s) or licensor are credited and that the original publication in this journal is cited, in accordance with accepted academic practice. No use, distribution or reproduction is permitted which does not comply with these terms.

One of the most important factors in professional development of a student during transition to a paradigm of competence-based education is their self-actualization as a future teacher and integration into professional space as a part of the social space. It makes sense that any selfactualization is most effective when it comes through the processes of self-examination, reflection, and especially, when the very fact of such actualization is a clearly defined purpose. For effective analysis (including self-examination), there are various forms and tools, both spontaneous and formalized, but at the present stage of development of professional education system there is still an issue of implementation of provisions of systemic approach to development and further integration into educational process of methodology of building student's capacities in various aspects and levels of analytical and reflective activity with appropriate content and technological support. As a rule, without effective and mobile tools, student's professional self-actualization goes spontaneously, nonsystematically, and often this process remains incomplete. In such context, the pressing issue is search and elaboration of effective methods and techniques of student's professional development and selfdevelopment, focused on processes of professional self-actualization, self-fulfillment in social and pedagogical environment, increase of social-reflective competence within professional preparation.

Conceptual aspects of the article are based on understanding principles of discursive essay writing method as one of effective tools for professional self-examination, raising the level of social and pedagogical competence, social reflection subject to development of adequate informative and technological support.

Literature review. The term, "discourse," is interdisciplinary and is the subject of research in philosophy, linguistics, social psychology, logic, sociology, literary studies, pedagogy, sociolinguistics, and others. Issues of essay studying (particularly as a method of training) were elaborated by V. Gutarov, Ye. Kirov, T. Milevska, G. Rudenko, K. Serazhym, N. Hamitov, I. Shevchenko, K. Shenderovsky. They interpreted its principles, core characteristics, and terms of 
effective implementation, particularly in educational process. A discursive essay is a rather complex phenomenon used in various fields of knowledge. "Discourse" term was created by S. Harrys, who developed distributive method in linguistics for distributive analysis of not only individual sentences but also texts, particularly considering them in the context of socio-cultural situation.

Researcher V. Gutarov, interpreting the term, "discourse," refers to its social potential. Discourse (Latin "discursus" - thinking, proof, argument) is defined as "super-phrase unity," "syntactic whole," "immersed in life" speech and is characterized by the multiplicity of its versatile entities [2, p. 163], a complex of extra-linguistic components that integrally determine its high analytical and communicative potential.

V. Karasyk interprets discourse as a text immersed in the situation of communication, which involves "a large number of dimensions," and complementary approaches in the study, including sociolinguistic ones $[4$, p. 5-6].

T. Milevska points out social and communicative nature of discourse, as well as its analytical and reflective aspect [6], treating the discursive approach as an alternative to sensual, contemplativeintuitive one, as a kind of verbalization of the thought process related to a particular problem. According to the author, in the depths of cognitive linguistics, the idea of discourse emerged not only as a dynamic process but also as a unit of analysis. With all the regularities of such a metonymic rethinking, it is obvious that it creates a number of problems for a researcher. Due to this, many scholars tend to select text as a unit of analysis, which, in turn, causes the need to separate terms: "discourse" and "coherent text."

Discourse, according to the above authors, can serve as a methodological basis for development of theoretical, technological approaches to development of methodological support for the process of discursive essay writing in professional training of teachers, creation of their personal basis.

The purpose of the article is to clarify principles, theoretical foundations of discursive essay and develop a method of writing discursive essay on social pedagogical topics on their basis.

Presenting key material. Summarizing the above, we should note that the discursive approach in professional education determines not only the technology of process of student's research and thinking over a certain problem, but also the mode of its presentation in the form of discursive level coherent text, which will be personally designated, authorial.

Discursive essay on social and pedagogical topics contains valid analytical and communicative potential and thus induces and gives reasons to new prospective thoughts on the problem, namely, its further processing at a higher level of complexity.

First of all, we proceed from the standpoint that discursive essay is one of the most effective methods of modern interactive training, the use of which fully corresponds to the purpose of professional education of a competent level, and uses its theoretical and logical basis. In order to choose the approach to developing didactic and methodical basis for writing an essay with regard to development of social reflection of a future teacher, which would provide an effective process of professional self-actualization and increase of general social and, particularly, social and pedagogical reflection, first of all, it is necessary to understand, on what theoretical grounds further detailed development of mechanisms, methods, techniques of work integrated into a comprehensive methodological toolkit will be based. When searching for appropriate educational formula, adequate content and methodological support to ensure systematic and adequate use of essay as a method of educational work, first of all, it is necessary to rely on its target orientation, which focuses on conducting a deep, multilevel self-examination based on given vectors and parameters.

Discursive essay is a method of teaching, based on characteristics of discursiveness, when the most important thing is not the result of analytical and synthetic reflections on the problem (argumentative essay) but the process itself, because such format meets the requirements for which conditional framework is provided and formalization of work is ensured, but the very processes of reflection, analysis, self-knowledge take place in a creative and free form and are characterized by informality, individuality of author's viewpoint, which makes it possible to ensure efficiency of analytical and reflective activity in accordance with the given vectors, while paying attention to individual features of researcher student's thinking.

First of all, discursive essay offers the format of a "frank conversation of student with themselves," setting correct problems, really relevant for themselves, the process of own professional development, rather than superficial, formally identified, and finding "honest" solutions. 
Developing methodical tools for optimizing the process of using essay method in the process of developing social reflection of a future teacher, we proceeded from the fact that this work should be holistic, complex, necessarily purposeful and predict step-by-step actions, starting from the preparatory stage, and completing the outcome and the after-effect (as a predicted prospect).

Preparatory stage. It is difficult to overestimate the importance of the system of preparatory work for such complex and yet not conventional type of creative educational work of students.

When it comes to development of new methods for formation of educational, professional, and social competencies, it is natural that a very effective form of work is collaborative, which is based on interactive basis. Positive aspects here include effect of synergy (a principle that indicates that the result of interaction of all system elements will be higher than the result being a mere summing up of the elements acting separately). In addition, psychologically favorable, competitive environment for generating ideas, offering algorithms, presentation of elements of successful past experience will increase motivation of each group member, and joint discussion of basic aspects of work will allow avoiding typical mistakes. That is why it is expedient to conduct preparation for essay writing in the form of a group lesson and in an interactive discussion form.

The first aspect and condition of successful preparation for work is deep and systematic understanding of theoretical material and methods of essay writing by a teacher who will provide students with methodological support in their work. Thus, within the limits of experimental study for mastering necessary theoretical basis, a teacher was offered to familiarize himself (to reproduce in memory) with special terminology on the problem, educational materials and scientific publications on a given topic, examples of essays written in the form of reflections and analytical exercises, etc.

In other words, a teacher has to master methods, theory, and practice of essay writing, use of essay method in general, as well as features of writing discursive essay in particular, to understand all general and specific aspects that may arise in the process of work. In order to consolidate material, writing of an essay by a teacher is suggested, because practical application of acquired knowledge will provide the most accurate understanding of problems and technology of the process. It is also worth noting that after implementation of the proposed action tasks, teacher naturally increases level of own social reflection and thus the overall level of professional and pedagogical competence.

In the process of preparation of a visual demonstration base, a teacher is encouraged to write another essay (if it is inappropriate to use the previously written one due to the presence of private teacher's thoughts that should not be made public), which would be the basis for demonstrating to students the form of work, its specificity and characterological aspects. The topic of such an essay can be freely chosen by a teacher and serve not only as a template for students, but also as a demonstration of thoughts on the topic, for example, "Discursive essay on social and pedagogical topic as an important tool of self-actualization for future teachers." The topic may be corrected according to the specifics of the circumstances in place. In case of writing and subsequent presentation of such an essay to a group, despite its function as a template, it will play a motivational role in perception by students of the work form proposed to them.

Given the specifics of the tasks set, the motivational aspect in such work is badly needed, because the very essence of it lies in the in-depth analysis and comprehension of the student themselves in the context of pedagogical training and further professional activities. Without adequate motivational support, the work performed will not be effective, since clearly defined motivation is an important prerequisite for achieving the goal set before writing a discursive essay. In addition to the above-mentioned recommendations on writing a thematic essay, a teacher is offered to conduct a fundamental discussion with the group to propose own vision and argumentation concerning importance of set goal, and then involve students in discussing motivational issues, stimulating them to explicit judgments, revealing contradictions that accompany the process of self-determination.

For example, at this preparatory stage, discussion subject may be the following: "Projection of students' perception of actual social and pedagogical activity: basic contradictions," where students would voice their reflections (content, logic, argumentation) regarding the vision of realities of the profession, its socio-reflective aspect. In such a way, the discussion can move to collective reflections on the most problematic aspects of profession that young teachers face (it is necessary to focus exactly on the problems of socialization, integration into socio-pedagogical space, professional, pedagogical, and social reflection) and verbalization of extremely valuable collective search for opportunities to prevent such problems in the learning process. This will make it possible to fully understand the 
importance of discursive educational work, more clearly identify specific problems that may become the topic for a discursive essay, identify an adequate goal and motivation for its achievement. The listed recommendations allow students to be as interested as possible in the topic and be involved in the process of preparation for its writing, internalizing the collective (models, methodologies, techniques, experience) into the individual, personally defined.

The next step in preparing to writing an essay is to familiarize students with the methodology of work itself, certain specifics of an essay, explanation of features of respective teaching method, its logistics, and other aspects. This is facilitated by a "template" written earlier by teacher in the process of presentation of which it is necessary to explain the very technology of forming thoughts, reflections, and their paper formalization. But it is necessary to emphasize the fact that the work is more creative, so adhering to any templates is not welcome. They are only shown to understand the essence of the process, and calquing and mechanical adherence to the template logic are erroneous.

Also, in the process of experimental training, a number of recommendations were selected. Students were invited to get acquainted with them before starting their work. They are presented in theses concerning the literary essay and to a large extent reflect the particularities of application of discursiveness principle, and can be adapted to writing of a discursive essay on social and pedagogical topic:

1. The easiest way to present the main idea is to express it in the first sentence of the paragraph, and then submit facts and examples of the idea. Each point shall be associated with the main sentence.

2. Impressions, thoughts and associations (according to I. Zvonenko) are "the three pillars of essays" determining the specificity of essay genre and metaphoricity of the language means used for its writing.

3. Free composition of an essay is subject to its internal logic, and the main idea of an essay should be sought in the diversity of author's reflections. The problem is considered from different points of view.

4. While rational combination of a fiction piece analysis with own considerations prevails in a work on literary topic, in an essay author's viewpoint is clearly expressed.

5. While individual peculiarities of author's style and language are welcome in traditional composition, individual author's style is the genre requirement for an essay.

6. Of course, an essay as a type of work on speech development shall not be confused with instructional technique for critical thinking development. The essence of "writing essay" in such technology can be formulated as follows: "I am writing in order to understand what I think about it."

7. Essay objective is not a story about life situation, but informing about ideas associated therewith, their explanations, unobtrusive attempts to convince readers of something.

8. This is a "free" writing on the offered topic, where independence, argumentation, originality of problem solving, and discussion are the most valued.

9. It is wonderful if an essay becomes an author's dispute with themselves [3].

Especially valuable in these positions are the approaches that determine the essence of principle of discursiveness in an essay, specify the format and indicate the conditions for its practical implementation. Adapting them to socio-pedagogical issues, you can note the following:

1. Presence of key semantic, system-oriented idea in the context of a certain socio-pedagogical problem, which is considered by essay's author student as particularly significant, having direct associations with their own life, social, future imaginary professional (quasi-professional) space. All thoughts should be centered on it and form "internal logic, logical interconnections between their components, heading towards comprehensive and deep understanding of the problem, self-determination in its context, search of his/her own answers to the problems posed by the student within the defined topic.

2. Discourse involves fixing the main focus on impressions, thoughts, and associations, which are "the three pillars of an essay," which a priori sets the format of educational work on fixing algorithms of thinking actions, which represent much higher value compared with conclusions drawn, often perceived as a goal in itself, an inherent worth. It should be noted that in the system of competent professional education, the process of educational activity is a subject of special professional value (ability to study), which determines the capacity for productive self-education activity, professional self-development, including social and pedagogical competence throughout life.

3. Independence, argumentation, originality, discussion must lead to actualization of internal "reasoning" over the socio-pedagogical problem, an attempt to find adequate external expression, 
including written presentation, which are more focused not on external control, and not even on selfcontrol, but on activation of self-educational processes, formation of socio-reflective competence based on "self-concept."

After passing the above stages, a student has increased level of understanding of the essence of this method of educational work, knows which of the basic principles shall be followed.

The process of writing an essay can be divided into several stages: thinking - planning writing - analysis/conclusion - correction/rewriting. A clear follow-up of these stages will allow to ensure integrity, systematic work with clear logic and possibility of further analysis and correction.

1. Thinking. First of all, you need to choose a topic. Topic should be close to a student who should be interested in it in terms of relevance of professional development, or it even should appeal to the student subjectively. In such case, the work will a priori have an appropriate level of personal orientation, inspire enthusiasm for work on its topic, the student will be more frank in setting questions and finding answers. Of course, a topic can be chosen freely, because the very specificity of the work is that any frameworks should be conditional, and the student should have full freedom of choice, both in defining work's topic, and in the algorithm and ways of its processing. Only general subject of work as the content of student's self-determination, personalized topic, common basic vectors of search of solutions to actual problems in its context should remain stable. Everything else (content, logic, structure, format of comprehension) is a student's personal work approach. Thus, in the process of experimental training, students were offered topics on socio-pedagogical subjects, which implemented orientation functions: 1. Letters from the future - "I am a teacher." 2. What features characterize modern professional teacher? 3. Who would I like to be in the eyes of my students? 4. Social problems of integration of innovative forms of education in modern realities of the profession of a teacher. 5. How do you understand the meaning of concepts: "successful teacher," "competent teacher," "social adaptation of the teacher?" 6 . What are the problems in the attitude of the society to a teacher and what are their causes? 7. Features of the profession of a teacher in Ukraine. 8. Low teacher status in Ukrainian society and related issues. 9. Ambitions of modern teacher and the tasks they set (must put) for themselves. 10. Increased social responsibility of a teacher, and how to handle it. 11. Ways for a young teacher to earn authority among students, colleagues, parents. 12. Using sociological terminology, describe your future pedagogical career.

After selecting a topic, one should proceed to direct thinking about problems of the topic and identify the key and most relevant aspects for the student, which will be semantic in the work. During the process of thinking, it is necessary to make written notes (thesis) - this will enable you to keep in mind important aspects and facilitate the planning process. When thinking about a problem, it is recommended to focus on the most controversial issues, find the "sharpest" angles of view on the problems, search for contradictions in concepts, viewpoints, content, etc. The special feature of a discursive essay is that there is no specifically set goal and writing of essay itself and questions/answers that will arise in the process of thinking make a goal in itself. In view of this, it is important only to follow the given general themes and, to the extent possible, follow the set conditional vectors (which, in the end, is not compulsory). Therefore, in the process of thinking it is not necessary to follow a specific purpose to find answers to the posed questions, the key thing is to "free" your thoughts proceeding from the selected topic and ultimately find out the essence of own experience in the given context, available viewpoints, level of their formation, that is self-identify the problem by correlating the general with individual, personally identified.

2. Planning. The planning stage is an important step in writing a quality essay. When it comes to work with a well-defined goal, proper planning allows to approach the goal step by step, building logical chains, without losing thinking algorithm and important aspects. But in case of a discursive essay, this stage is not so critical as, for example, in an argumentative essay. While working on a discursive essay, this stage allows to accumulate information on a subject that is interesting to the author and "extract" it gradually, as if from a repository. In such approach, when paying attention to analytical work on some aspects, one should not lose others, not less important. Despite this, among all problematic areas, one should be highlighted - the key one which will become a starting point in the process of thinking and can (though not necessarily) be the core of entire essay construct. This will guarantee a clearer, vector-defined hierarchical structure of work. Other, less important aspects can be classified both by importance or using any other hierarchical system and actualized in the process of thinking. 
Given the foregoing, it is necessary to make an indicative (to a certain extent conditional) plan for the sake of visibility and ease of orientation in the work. It can have the following steps:

1. Future essay can be divided into conditional 3 parts: introduction, which will indicate the key topic, explain its relevance and set the most important questions; main part, where the process of thinking and finding answers or setting new questions will take place; conclusion - citation and free interpretation of impressions and emotions that arose during work on the essay, indication of answers to the questions posed, which were received during the process of thinking, the list of issues that arose during writing of the essay but were not actualized until work on it started.

2. Approximate percentage of parts of work may be as follows: $25 \%|50 \%| 25 \%$. This form of composition is all-purpose for many types of creative work and proves its efficiency in practice. In essence, an essay on socio-pedagogical topics can be associated (in particular, to acquire situational attributes) with a work on free topic, a summary, a scientific treatise, and others like that. Its advantage over large creative forms of work is the priority of own thinking over the problem, getting new experience in the context of certain problems.

3. It is necessary to briefly describe the topic, analyze its relevance to the author in the introduction. Vectors which the author plans to use for the issue can be specified. Also (if relevant to the specifics of work topic), it is necessary to a priori "provoke" a conflict as the basic starting point for further thinking, pointing out several controversial viewpoints on the issue. This will allow to consider the issue more coherently and in different perspectives, which will positively affect author's understanding of the issue in general. At the beginning, while forming the questions, it is important to abstract as much as possible from one or another viewpoint and ensure that the author does not have pre-prepared answers to the posed questions; in other words, the author has to set a kind of "challenge" to find answers to them.

4. The main part is the most arbitrary and does not have clear instructions. It may include any intellectual and analytical actions that the author finds relevant in the process of working on the problem. It is important to adhere to the key themes, chosen vectors, and involve all aspects that were identified at the thinking and planning stage as important.

5. The final part can be a kind of "work report". Such report is provisional and must include both essential and emotional-sensual aspects: feelings the author had in the process of working on the essay, emotions that they experienced during thinking about the problems. It is also necessary (the best thing to do this in the form of thesis) to indicate the answers received (even if they are perceived as intermediate), mark new questions "generated" in the process of discursive analysis for further thinking.

3. Writing. Having passed all the previous stages, student can go on to direct work on writing an essay, and if all the stages were worked out in good faith, according to the instructions, the student has a complete set of knowledge and tools to efficiently write an essay on socio-pedagogical topics. This means that the writing process itself will not cause any difficulties. Work form such as an essay involves creative approach and a discursive essay gives even more freedom of action, therefore the author shall select style, scale, level of deepening in the problem, importance of certain questions, etc. As already noted above, the only requirements are following the topic and vectors individually chosen or proposed above, which will be the basis for thinking over the problem.

Despite the free form of essay writing, we consider it worthwhile to focus on relevant tips that can optimize the process:

1) Thoughts and considerations can be expressed in free form, but it is recommended to mark them for convenience of orientation in the work and effective post-analysis.

2) Assumptions, hypotheses, and intermediate conclusions should be argued, even if the arguments are subjective.

3) Need to focus on conciseness and clarity of expressions, imagery, metaphoricity, etc. are welcome.

4) It is compulsory to oppose some assumptions and arguments to others, which allows to comprehensively consider the issues.

5) An essay can have vertical or structure, but it is important not to mix them and to follow the selected form. If the integration of forms is necessary, it shall be arranged.

6) It is also necessary to follow basic configuration of the constituents of essay writing in the form, introduction - main part-conclusion. 
Following these recommendations, the student will be able to write the work efficiently, paying attention to important aspects and requirements to ensure its quality.

4. Analysis and conclusions. Correct work analysis is as important as writing an essay on social-pedagogical topic itself. The key thing here is not a student's ability to formulate a list of clear work conclusions, formulation of answers to the posed questions. The specifics of discursive essay indicates that the main purpose of writing of this type of creative work is the actual process of thinking over the problem and setting sharp questions, thus, the entire focus of analytical work should be on the process rather than the result. It is important to analyze the extent of the author`s frankness with themselves, the depth of immersion in the problem, acuteness of posed questions, and extent of diversity and scale of their comprehension process. Emotional component is also important - it is necessary to determine whether the work on the essay was fascinating, how the author was emotionally immersed in thinking about the problem, whether the topic was chosen correctly in the context of its importance and urgency to the author, etc. In order to clearly analyze degree of success of the work, a number of criteria were formed. For the ease of use, they are presented in the table.

Table 1. General criteria for writing a discursive essay

\begin{tabular}{|l|l|l|}
\hline Criterion & Requirements & Score \\
\hline $\begin{array}{l}\text { Theoretical } \\
\text { competence in the } \\
\text { problem }\end{array}$ & $\begin{array}{l}\text { - level of theoretical preparation for essay writing, level of orientation } \\
\text { in terms and mechanisms used when working on the essay, } \\
\text { understanding tasks and essence of processes that determine them. }\end{array}$ & \\
\hline $\begin{array}{l}\text { Content analysis } \\
\text { and assessment }\end{array}$ & $\begin{array}{l}\text { - level of immersion in socio-pedagogical problems, level of } \\
\text { complexity and diversity of mental structures in the thinking process, } \\
\text { complexity of analytics, } \\
\text { - application of the diversity principle in consideration of problems, } \\
\text { involvement of alternative viewpoints, creation of controversial } \\
\text { views, triggering conflicts of thoughts and interests, width of raised } \\
\text { issues range, etc. }\end{array}$ & \\
\hline Style and logistics & $\begin{array}{l}\text { - clarity and clearness of expressions, logic and structuring of } \\
\text { connections between hypothesis and argument, individual style, } \\
\text { subjectivity and independence of thoughts, general stylistics; } \\
\text { relevance of work and used tools to the work genre. }\end{array}$ & \\
\hline Work layout & $\begin{array}{l}\text { - whether the work corresponds to the basic requirements for design } \\
\text { of such kind of students creative work, observance of lexical, } \\
\text { phraseological, grammatical and stylistic norms of the Ukrainian } \\
\text { literary language; competent text layout with full compliance with the } \\
\text { rules of Ukrainian spelling, stylistics, and punctuation. }\end{array}$ & \\
\hline
\end{tabular}

Before or after essay writing, a student is proposed to develop own assessment scale for each block of criteria according to own personal perceptions of their content and importance-based hierarchy. After that, a student can assess each block according to the defined scale and give the work to the teacher for assessment. The teacher will apply a formalized, common scale of criteria and quality indicators, correlating it with the one specified by the student. After summarizing independent assessments and characteristics from each block of criteria separately, as well as the work in general, the student can assess the overall performance according to own level of aspiration and motivation. Such approach is offered precisely because the work has a subjective nature and therefore the author themselves should first assess its quality, further correlating it with evaluative judgments of the teacher, which will add objectivity to the final result. We proceed from the viewpoint that the assessment process should contribute to the development of student's capacity for efficient self-assessment.

5. Adjusting or rewriting the work. The specifics of writing of an essay on socialpedagogical topic is that it is implemented on a self-regulating basis and has a clear individually defined professional motivation. If the essay is written formally (to get score from a teacher), it does not fulfill the function of development of social reflection, social-pedagogical competence. Therefore, if a student is satisfied with the score, it means that such score corresponds to their professional, social-reflection potential at a certain stage of development. Student themselves should take decision on continuation of work on the essay. Further work may relate to making adjustments in essay writing 
in accordance with the process and results of diagnosis and analytical activity at the final stage, or maybe rewriting the work in case the student has such a need and feels ready for a new attempt using a qualitatively higher level of the formed competencies.

Conclusions. Thus, the problem of expediency and efficiency of using discursive essay writing method on social-pedagogical topic in the process of professional training of future teacher is complex and multifunctional. It requires intensification of theoretical studies concerning more profound and systematic understanding of discourse in education, content and technological fundamentals of its use at the stage of transition to a competent paradigm based on the processes of student's professional, personal self-development, and self-actualization in its context. The proposed methodology of stage-by-stage preparation for writing a discursive essay on socio-pedagogical problems, assessment of its performance is conditional and can be modified to satisfy specific needs of educational practice, specifics of the content of a certain discursive subject.

\section{REFERENCES}

1. Academic discourse and discourse approach in teaching of foreign languages [Electronic resource]: Materials of International Round Table, Minsk, April 16-18, 2015/under the general editorship of O. Lushchinskaya, A. Popova, Ye. Tikhomirova. - Minsk: BGU, 2015.

2. V. Gutarov. About the definition of scientific philological discourse [Text]/V. Gutarov//Bulletin of Kharkiv National University named after V. Karazin No. 567. 2002. P. 163-170.

3. I. Zvonenko. Essay as a genre of student's composition. Kh.: Osnova Publishing Group, 2003. 78 p.

4. V. Karasyk, On the types of discourse. Language personality: institutional and personal discourse: collection of scientific articles. Volgograd: Peremena, 2000 (a). P. 5-20.

5. Ye. Kirov. The chain of events - discourse/text - concept//Actual problems of linguistics and intercultural communication. Linguodidactic aspects of intercultural communication: Materials of Scientific Session of the Faculty of Linguistics and International Communications of Volgograd State University. - Volgograd, April, 2003: collection of scientific articles. Volgograd: Volgograd Publishing, 2004. Issue 2. P. 29-41.

6. T. Milevska. On the concept of "discourse" in line with communicative approach//Materials of the International Scientific and Practical Conference: Communication: Theory and Practice in Various Social Contexts (Communication 2002) Part 1. Pyatigorsk: PGLU Publishing, 2002. P. 188-190.

7. K. Serazhym. Discourse as a sociolinguistic phenomenon: methodology, architectonics, variation: [based on materials of contemporary newspapers]: monograph/K. Serazhym. K., 2002. 392 p.

8. I. Shevchenko. Cognitive-communicative paradigm and discourse analysis/I. Shevchenko//Discourse as a cognitive-communicative phenomenon. Kharkiv: Konstanta, 2005. P. 9-20.

9. Dijk, T. van (1998), Ideology: A Multidisciplinary Approach. London: SAGE Publications, online: psyberlink.flogiston.ru/internet/bits/vandijk2.htm. 